Revista Eureka sobre Enseñanza y Divulgación de las Ciencias

ISSN: 1697-011X

revista.eureka@uca.es

Universidad de Cádiz

España

\title{
¿Plásticos sí o plásticos no? Trabajando prácticas científicas con estudiantes de bachillerato
}

Cascarosa Salillas, Esther; Pozuelo Muñoz, Jorge; Calvo Zueco, María Elena

¿Plásticos sí o plásticos no? Trabajando prácticas científicas con estudiantes de bachillerato

Revista Eureka sobre Enseñanza y Divulgación de las Ciencias, vol. 19, núm. 1, 2022

Universidad de Cádiz, España

Disponible en: https://www.redalyc.org/articulo.oa?id=92068491020

DOI: https://doi.org/10.25267/Rev_Eureka_ensen_divulg_cienc.2022.v19.i1.1502 
Educación científica y sostenibilidad

\section{¿Plásticos sí o plásticos no? Trabajando prácticas científicas con estudiantes de bachillerato}

Plastics, yes or not? Developing scientific practices with high school students

Esther Cascarosa Salillas

Departamento de Didácticas Especificas, Área de Didáctica

de las Ciencias Experimentales, Facultad de Educación,

Universidad de Zaragoza, España

ecascano@unizar.es

iD https://orcid.org/0000-0002-3696-7673

Jorge Pozuelo Muñoz

Departamento de Didácticas Especificas, Área de Didáctica

de las Ciencias Experimentales, Facultad de Educación,

Universidad de Zaragoza, España

jorge.pozuelo.munoz@gmail.com

iD https://orcid.org/0000-0002-9223-6832

María Elena Calvo Zueco

Colegio Internacional Ánfora, Cuarte de Huerva,

Zaragoza, España

ecalvo51@hotmail.es

iD https://orcid.org/0000-0001-8079-7643
DOI: https://doi.org/10.25267/

Rev_Eureka_ensen_divulg_cienc.2022.v19.i1.1502

Redalyc: https://www.redalyc.org/articulo.oa?

$\mathrm{id}=92068491020$

Recepción: 11 Septiembre 2021

Revisado: 23 Noviembre 2021

Aprobación: 24 Noviembre 2021

\section{ReSUMEN:}

Presentamos un proyecto desarrollado con alumnado de $1^{\circ}$ de Bachillerato en relación al tema de los plásticos, sus principales aplicaciones y los problemas medioambientales que se derivan de su uso. Partiendo de una colaboración docente del centrodocentes de universidad, se diseñó una secuencia de actividades para desarrollar la competencia científica a través de las prácticas de argumentación, indagación y modelización. Se recogieron datos a través de la grabación de audio y video, que fueron transcritos y analizados. Los resultados obtenidos muestran altos niveles de desempeño de las destrezas implicadas en la práctica científicas trabajadas y un alto grado de implicación e interés por parte de los estudiantes, basados en el papel activo que han desarrollado en el trabajo guiado a través de preguntas.

Palabras Clave: Bachillerato, Plásticos, Prácticas científicas, Reacciones químicas.

\section{AbstraCt:}

The project was developed with 1st year high school students is presented in relation to the subject of plastics, its main applications and the environmental problems that derive from its use. Starting from a teaching collaboration of the university teaching center, a sequence of activities was designed to develop scientific competence through argumentation, inquiry and modeling practices. Data were collected through audio and video recording, which were transcribed and analyzed. The results obtained show high levels of performance of the skills involved in the scientific practice studied and a high degree of involvement and interest on the part of the students, based on the active role they have developed in the work guided through questions.

KEYWORDS: High School, Plastics, Scientific practices, Chemical reactions. 


\section{INTRODUCCIÓN}

La enseñanza y aprendizaje de las reacciones químicas es un contenido fundamental del currículo de química que, en España, se aborda en los cursos de educación secundaria obligatoria y bachillerato. Algunos autores han comprobado la dificultad que encuentra el alumnado en el aprendizaje de este contenido, concluyendo que la experimentación facilita el proceso (González y Crujeiras, 2016). En este sentido, autores como Bevins y Price (2016), Jiménez-Aleixandre y Crujeiras (2017) o Mosquera Bargiela, Puig y Blanco Anaya (2018) consideran que las prácticas científicas (indagación, argumentación y modelización) son un método para enseñar ciencias, a través del planteamiento de preguntas, que ayuda a promover habilidades de investigación en los estudiantes y a interiorizar nuevo conocimiento. En concreto González Rodríguez y Crujeiras Pérez (2016) concluyeron la adecuación de trabajar las reacciones químicas (tema implícito en el que nos ocupa) a través de la indagación en actividades experimentales.

La indagación es un proceso intencional de diagnóstico de problemas, que requiere la identificación de asunciones, la aplicación del pensamiento lógico y crítico, y la consideración de explicaciones alternativas (Ariza et al., 2016) y está en relación directa con cómo los científicos estudian el mundo natural y proponen explicaciones basadas en las pruebas derivadas de su trabajo (Martin-Hansen, 2002). La indagación parte del planteamiento de preguntas que se formulan inicialmente y que actúan como generadoras y organizadoras del saber (Crawford, 2007). Este cuestionamiento despierta el deseo de conocer cosas nuevas y ayuda a reflexionar sobre el propio saber y el proceso de aprendizaje (Jiménez-Aleixandre y Crujeiras, 2017). En el contexto escolar, se ha demostrado que realizar preguntas abiertas, mostrar actitud de escucha y facilitar recursos a los alumnos y alumnas para que puedan responder favorece el pensamiento divergente, las respuestas más completas y la participación en debates en el aula (Mosquera Bargiela, Puig y Blanco Anaya, 2018). La indagación a través de la experimentación forma parte del proceso de elaboración de modelos en el marco escolar, en las fases de elaboración y puesta a prueba de los modelos mentales, cuyo objetivo es la resolución de desafíos prácticos, que son muy útiles para la comprensión procedimental de la ciencia, es decir, para aprender los procesos que caracterizan la investigación (González Rodríguez y Crujeiras Pérez, 2016).

El análisis de la argumentación en el aula permite identificar procesos de aprendizaje u obstáculos al mismo, de acuerdo a Jiménez-Aleixandre y Díaz-de Bustamente (2003), ya que la argumentación en sí es representativa de los procesos que tienen lugar en la mente del alumnado. La valoración de estos procesos a través de la evaluación de la argumentación, debe realizarse en los discursos naturales entre el alumnado, que ocurren cuando los estudiantes discuten sobre cuestiones de ciencia y no en el análisis de las respuestas que puedan dar en cuestionarios o entrevistas.

La modelización permite a los estudiantes crear, revisar y usar modelos con el fin de entender, saber explicar y predecir fenómenos (Mosquera Bargiela, Puig y Blanco Anaya, 2018). Así, se puede evaluar la práctica de la modelización a través de las explicaciones y predicciones que los estudiantes realizan en su práctica científica.

Según Hodson (1994), a los estudiantes les gusta saber lo que están haciendo porque si no les desconcierta, y lo que valoran son los desafíos cognitivos, el ser capaces de responderse ellos mismos las preguntas. Eso implica que los trabajos que se diseñen deben ser adecuados para que el alumnado tenga una medida de control e independencia suficiente, sin que éstos constituyan una interferencia en el proceso de aprendizaje. En este sentido, el contexto utilizado debe generar curiosidad en el alumnado y para ello son idóneos los contextos reales y cercanos a su quehacer cotidiano (Caamaño, 2018). Para ello, las controversias sociocientíficas pueden resultar de utilidad, pues abordan problemas científicos de tipo social, ambiental o ético que afectan a la vida de las personas (Sadler y Zeidler, 2005). Este tipo de controversias ayuda a desarrollar la competencia científica mediante el desarrollo de prácticas científicas como la argumentación y la modelización (Uskola, Burgoa y Maguregi, 2021). Es por eso que en este proyecto se trabajó sobre el problema medioambiental de la gestión de los plásticos. 
Al mismo tiempo que el alumnado investiga sobre esos nuevos materiales, necesitan conocer qué es un plástico y la problemática de los residuos plásticos, desde la propia base científica (tema que también abordan Crujeiras-Pérez y Brocos, 2021). En este trabajo, se ha desarrollado una secuencia de actividades con las que trabajar los plásticos y su gestión, a través de prácticas científicas de indagación, argumentación y modelización. A su vez, se busca construir conciencia sobre los problemas medioambientales que generan los plásticos, respondiendo a uno de los objetivos clave de la enseñanza de la ciencia de los últimos años (OCDE, 2016).

Contemplando, tanto la controversia de los plásticos, como los beneficios cognitivos para el alumnado que se pueden alcanzar a través de las prácticas científicas en el aula, planteamos si es posible trabajar estas prácticas a través de una secuencia de actividades diseñada para el contexto específico de investigación. De aquí nace la pregunta de investigación que persigue responder este trabajo: ¿qué prácticas científicas se pueden trabajar a través de un proyecto sobre los plásticos en bachillerato?

\section{Metodología}

Esta secuencia didáctica se ha desarrollado a lo largo del curso 2020/21 con los alumnos/as de $1^{\circ}$ Bachillerato (16-17 años) que cursaban la asignatura de Física y Química en un centro de Zaragoza. Este trabajo nace de la colaboración existente entre el profesorado del centro junto con el profesorado de la Universidad. Debido a las circunstancias derivadas de la pandemia y la fragmentación de los grupos, se ha trabajo con un grupo compuesto por 6 personas, 5 chicos y 1 chica, habituados a los trabajos prácticos.

El proyecto se ha diseñado para trabajar las prácticas científicas en relación a un tema que tiene un interés doble: por un lado, un interés curricular, ya que se trabajan los contenidos relativos a los plásticos que marca el currículo de Física y Química para $1^{\circ}$ de Bachillerato (Real Decreto 1105/2014) (Bloque 3: Reacciones químicas, Bloque 4: Polímeros de origen natural y sintético: propiedades. Reacciones de polimerización. Fabricación de materiales plásticos y sus transformados: impacto medioambiental.),y, por otro lado, el interés existente debido a la actualidad de la problemática social y científica que supone la gestión de los plásticos en el ámbito de la conservación medioambiental, y también dentro de la propia enseñanza de las ciencias (OCDE, 2016). A su vez, es una oportunidad para trabajar procedimientos y actitudes hacia la ciencia gracias al interés que despiertan este tipo de cuestiones entre el alumnado (Díaz y Jiménez-Liso, 2012).

Todas las sesiones del proyecto se han grabado a través audio y vídeo, han sido transcritas y analizadas cualitativamente identificando las operaciones trabajadas relativas a cada práctica científica. Se han recogido también anotaciones basadas en una observación estructurada y fotografías de los productos obtenidos en algunas de las actividades, que ilustran el desarrollo del proyecto.

\section{Diseño del proyecto}

En este proyecto se plantea una secuencia guiada donde el alumnado trabaja desde una perspectiva que permita desarrollar las destrezas propias de la investigación científica y así modelar el trabajo de los científicos. Además de buscar la motivación e implicación cognitiva del alumnado a través de un reto (Couso, 2014), se busca promover destrezas de investigación, fomentar la argumentación basada en s, el contraste, evaluación de ideas alternativas, y la construcción de teorías y modelos científicos explicativos. Esta estrategia enmarca el papel activo y de razonamiento del alumnado en el proceso de enseñanza y aprendizaje.

Siguiendo el objetivo de trabajar las prácticas científicas a través de las actividades del proyecto, se diseñó una secuencia en dos fases, de seis actividades en total (ver figura 1). 


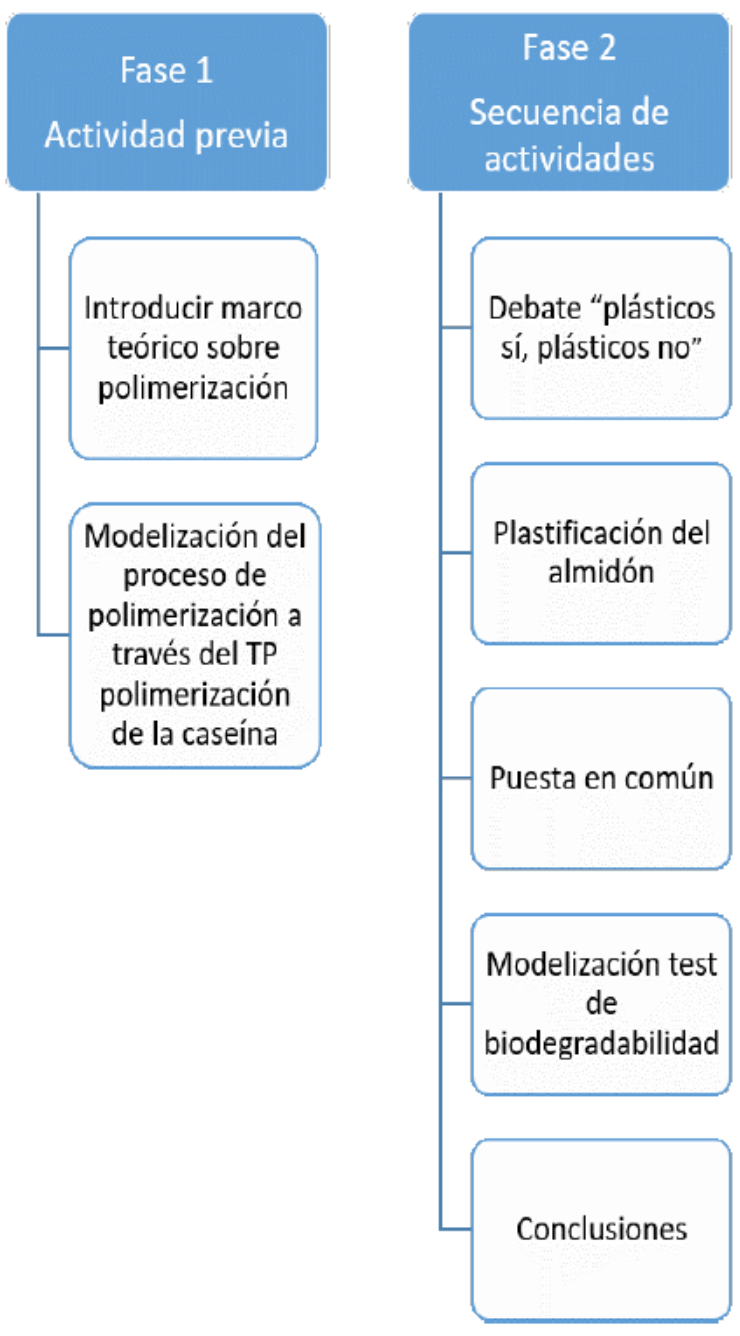

FIGURA 1

Fases del proyecto: actividades desarrolladas.

\section{Fase 1}

En la primera fase se proporciona el marco teórico conceptual necesario sobre las reacciones de polimerización. Sin perder de vista que los objetivos de aprendizaje para el alumnado, engloban los contenidos relativos a las reacciones de polimerización, se desarrolló una sesión teórica donde se introdujeron los derivados del petróleo y nociones previas sobre las reacciones de polimerización y sus principales aplicaciones. En segundo lugar, se trabajaron las reacciones de polimerización con un ejercicio de modelización con unos clips (de colores distintos), donde un clip representa un monómero, y cada color se identifica con un monómero distinto. El alumnado debía encadenar los clips para la formación de la cadena, para de esta manera introducir los conceptos de dímero, homopolímero y heteropolímero. Por último, dentro de las actividades previas desarrolladas en la fase 1, se planteó un trabajo práctico (TP) donde se experimentó con una reacción de polimerización y el cambio químico de este tipo de reacciones (Müller, 2020). Entre los objetivos a conseguir con estas actividades previas, uno fue introducir al alumnado a los trabajos prácticos 
de polimerización con un ejemplo concreto, la polimerización de la caseína, sobre el que tuvieron que experimentar e interpretar los resultados de dicha actividad experimental.

\section{Fase 2}

En una segunda fase, se implementa una secuencia diseñada con el fin de que los estudiantes desarrollen el espíritu crítico, en relación al problema de los plásticos, con una base científica, es decir, que a través de la propia experimentación lleguen a formar una opinión crítica sobre el problema medioambiental. Para ello se desarrollan cinco actividades, secuenciadas como se muestra en la figura 1.

Actividad 1: Cuando se inicia un proyecto de enfoque científico, se debe partir de hechos u objetos que han generado curiosidad en los estudiantes (Cascarosa, Mazas, Martínez-Peña y Gil-Quílez, 2019), lo que despierta una motivación inicial hacia su propio proceso de aprendizaje (Mazas, Cascarosa y Mateo, 2021). El uso de plásticos es un tema de actualidad con un profundo trasfondo científico, con el que los estudiantes se sienten vinculados ya que los plásticos son de uso cotidiano para ellos (Caamaño, 2018). El objetivo de la actividad es, dándoles fuentes de información científica, que se formen para poder argumentar su posición, a favor o en contra del uso de plásticos. Para desarrollar una argumentación de calidad, esta debe estar basada en pruebas o datos (Jiménez-Aleixandre y Crujeiras, 2017) que en este caso deben identificar dentro de los textos aportados. Una vez posicionados a favor o en contra, se desarrolló un debate donde los estudiantes argumentaron sus posicionamientos. Estas opiniones constituyen en realidad sus hipótesis de partida ante el uso de los plásticos, que se verá refutada o aceptada al finalizar el proyecto completo.

Para que el alumnado tenga argumentos con base científica para aceptar o refutar su posición inicial frente al uso de plásticos, es necesario que conozcan qué es un plástico desde el punto de vista químico, deben conocer su composición y el proceso de fabricación del mismo, para ello se diseñó la segunda actividad.

Actividad 2: En la segunda actividad, también a través del planteamiento de preguntas, los alumnos indagan sobre los procesos de polimerización. Para ello, realizan una actividad experimental en la que tienen que seguir un procedimiento de polimerización para conseguir un plástico a partir de almidón. En este procedimiento, la docente les da indicaciones generales para realizar la reacción de polimerización, pero deben ser los propios alumnos los que tomen decisiones sobre las variables del proceso (por ejemplo, la temperatura o el grado de agitación de la mezcla en la reacción de polimerización). Se les pide que realicen el procedimiento por duplicado con el fin de que obtengan dos muestras y comprueben si en los dos casos obtienen el mismo resultado o no. Una vez obtenidas las dos muestras de polímero, deben reflexionar sobre los resultados obtenidos y el procedimiento seguido para obtenerlo. En esta actividad los alumnos deben observar lo que ocurre en la reacción, formular hipótesis en relación a las variables de reacción, explorar a través de la realización de una segunda experimentación en la que repiten en proceso e interpretar los resultados obtenidos.

Actividad 3: En la siguiente actividad, cada grupo presenta los resultados que ha obtenido, ponen en común lo que han observado, las hipótesis que han formulado, las pruebas que han realizado para comprobarlas y extraen conclusiones al respecto. De esta manera, los alumnos trabajan la práctica científica de la argumentación, a través del uso e identificación de pruebas, la justificación de respuestas y la extracción de conclusiones (Jiménez-Aleixandre y Crujeiras, 2017).

Actividad 4: Una vez que el alumnado conoce, de manera práctica, qué es un plástico y en qué consiste el proceso de plastificación, para poder tomar decisiones sobre el uso de los plásticos, debe tener conocimientos sobre su gestión, y en concreto, en el proyecto trabajamos sobre la degradabilidad de los mismos una vez que ya no tienen uso. Para ello, la docente presenta a los alumnos una serie de muestras plásticas y les pide que identifiquen si el polímero es biodegradable o no. Para ello, se les suministra varios artículos científicos que ellos deben leer en profundidad y a partir de ello deben diseñar un test de biodegradabilidad de plásticos y comprobar la biodegradabilidad de esas muestras. En esta cuarta actividad, los alumnos modelizaron 
un test de biodegradabilidad: lo diseñaron tomando como base datos científicos, los pusieron en marcha, comprobaron los resultados de los test sobre muestras de plásticos y sacaron conclusiones.

Actividad 5: Finalmente, se llevó a cabo una sesión donde los alumnos debían retomar su hipótesis inicial sobre el uso de los plásticos y, poner en común toda la información obtenida a lo largo del proyecto. No hay que olvidar que, la puesta en común de los conocimientos que van adquiriendo con base en la experimentación a lo largo del proyecto es un proceso social que ayuda al aprendizaje del alumno (García Carmona, 2012). A través de la comunicación de los conocimientos que los alumnos han ido adquiriendo, debían retomar la hipótesis inicial sobre el uso de plásticos y aceptarla o refutarla. En resumen, en esta actividad, se trabajó la argumentación a través del uso de pruebas que habían obtenido a lo largo de todo el proyecto, la justificación de las respuestas que dieron y finalmente extrajeron conclusiones sobre el tema trabajado. Aunque en esta actividad consideramos que se trabajó principalmente la argumentación, también la modelización se llevó a cabo, ya que los alumnos establecieron relaciones entre lo trabajado y el sistema que rodea al proyecto y transfirieron el aprendizaje entre actividades, el alcanzado entre ellos mismos (interacción alumno-alumno) y a la docente (Hinojosa y Sanmartí, 2015).

Hemos clasificado las actividades diseñadas en la secuencia didáctica en la tabla siguiente, atendiendo a la operación o destreza científica principal que se desarrolla en cada una de ellas. Indicamos solamente la práctica que consideramos principal, siendo conscientes de que en algunas de ellas se trabajan al mismo tiempo más de una práctica científica, y que el límite de la dimensión teórica y discursiva entre unas y otras no siempre está clara (Couso, 2014).

TABLA 1

Actividades secuenciadas y operaciones (o destrezas) trabajadas en ellas.

\begin{tabular}{|c|c|c|c|}
\hline \multicolumn{2}{|c|}{ Actividad } & Práctica científica & Operación o destreza científica \\
\hline 0 & Polimerización de la caseína & Indagación & $\begin{array}{l}\text { Observar, experimentar-manipular, interpretar } \\
\text { información }\end{array}$ \\
\hline 1 & $\begin{array}{l}\text { Debate "plásticos sí, plásticos } \\
\text { no" }\end{array}$ & Argumentación & Usar e identificar pruebas, justificar respuestas \\
\hline 2 & Plastificación del almidón & Indagación & $\begin{array}{l}\text { Observar, formular preguntas, emitir hipótesis, } \\
\text { experimentar-manipular, explorar, interpretar } \\
\text { información }\end{array}$ \\
\hline 3 & $\begin{array}{l}\text { Puesta en común y búsqueda de } \\
\text { respuestas }\end{array}$ & Argumentación & $\begin{array}{l}\text { Usar e identificar pruebas, justificar respuestas, } \\
\text { extraer conclusiones }\end{array}$ \\
\hline 4 & $\begin{array}{lll}\text { Modelización } & \text { test } & \text { de } \\
\text { biodegradabilidad } & & \\
\end{array}$ & Modelización & $\begin{array}{l}\text { Explicar fenómenos, diseño de procedimientos } \\
\text { Uso de modelos }\end{array}$ \\
\hline 5 & $\begin{array}{l}\text { Conclusiones "plásticos } \\
\text { plásticos no" }\end{array}$ & Argumentación & $\begin{array}{l}\text { Usar e identificar pruebas, justificar respuestas, } \\
\text { extraer conclusiones }\end{array}$ \\
\hline
\end{tabular}

Los alumnos desarrollan todas las actividades a través del planteamiento de preguntas secuenciadas para la consecución de los objetivos de aprendizaje. En la Tabla 2, se muestran las preguntas que los alumnos deben ir respondiendo en cada una de las actividades y que les sirven de guía para el desarrollo de cada actividad. 
TABLA 2

Secuencia de preguntas formuladas en cada actividad.

\begin{tabular}{|c|c|}
\hline SECUENCLA ACTIV TD ADES & PREGUNTAS PREV LAS \\
\hline $\begin{array}{l}\text { Fase 1: } \\
\text { ACTIVIDAD 0: } \\
\text { Modelización y TP Caseína }\end{array}$ & $\begin{array}{l}\text { ¿Qué es un polímero?, ¿qué tipos de enlaces tienen? Representa un } \\
\text { homopolímero, un heteropolímero, un dímero y un trímero. Reconoce } \\
\text { macromoléculas naturales y sintéticas. ¿Qué mecanismos de reacción } \\
\text { tienen lugar? }\end{array}$ \\
\hline $\begin{array}{l}\text { Fase 2: } \\
\text { ACTIVIDAD 1: } \\
\text { Debate "Plásticos sí, plásticos no" }\end{array}$ & $\begin{array}{l}\text { ¿uál es el principal problema de los plásticos?, ¿se puede vivir sin } \\
\text { plásticos?, ¿qué líneas de trabajo se plantean para paliar el problema } \\
\text { medioambiental de los plásticos? Desde la química, ¿qué materiales } \\
\text { alternativos se están trabajando? }\end{array}$ \\
\hline $\begin{array}{l}\text { Fase 2: } \\
\text { ACTIVIDAD 2: } \\
\text { Plastificación del almidón }\end{array}$ & $\begin{array}{l}\text { ¿Qué hace falta para elaborar un bioplástico?, ¿cuál es la proporción } \\
\text { optima almidón/plastificante?, ¿hay diferencia según el procedimiento } \\
\text { seguido?, ¿cómo imaginas el proceso de trasformación del almidón a } \\
\text { bioplástico? ¿crees que algunas de estas variables influyen en la } \\
\text { degradabilidad del plástico? }\end{array}$ \\
\hline $\begin{array}{l}\text { Fase 2: } \\
\text { ACTIVIDAD 3: } \\
\text { Presentación de resultados }\end{array}$ & $\begin{array}{l}\text { ¿ué diferencia hay entre las dos producciones que se presentan?, } \\
\text { ¿habéis seguido el mismo procedimiento o ha cambiado la composición? } \\
\text { ¿uál diríais que es el mejor procedimiento, para qué y por qué? ¿Con } \\
\text { qué problemas os habéis encontrado en la práctica?, ¿cómo lo habéis } \\
\text { solucionado? }\end{array}$ \\
\hline $\begin{array}{l}\text { Fase 2: } \\
\text { ACTIVIDAD 4: } \\
\text { Diseño test de biodegradabilidad }\end{array}$ & $\begin{array}{l}\text { ¿Cuál de los plásticos que tenemos sobre la mesa es más biodegradable?, } \\
\text { ¿cómo podemos comprobarlo? ¿influye alguna de las variables } \\
\text { identificadas en la actividad 2, sobre la biodegradabilidad del plástico? }\end{array}$ \\
\hline $\begin{array}{l}\text { Fase 2: } \\
\text { ACTIVIDAD 5: Conclusiones } \\
\text { "plásticos sí, plásticos no" }\end{array}$ & $\begin{array}{l}\text { ¿Todos los plásticos son iguales? ¿Se pueden usar plásticos que generen } \\
\text { un impacto bajo sobre el medio ambiente? }\end{array}$ \\
\hline
\end{tabular}

El desarrollo de las tres prácticas científicas se valora en el global de la secuencia llevada a cabo. Las prácticas científicas de la argumentación y de la modelización se evalúa a través de las operaciones establecidas por Mosquera Bargiela, Puig y Blanco Anaya (2018). Para analizar la argumentación, tenemos en cuenta el uso e identificación que los alumnos hacen de las pruebas, de la justificación de sus respuestas y de la extracción de conclusiones. Para evaluar la modelización, contemplamos las relaciones que los alumnos establecen entre lo trabajado y el sistema que rodea al proyecto, la transferencia del aprendizaje entre actividades, la explicación de los fenómenos observados y el uso de modelos (Hinojosa y Sanmartí, 2015).

Finalmente, se diseñó una rúbrica de evaluación de las destrezas del trabajo de indagación, tomando como referencia las propuestas por Crujeiras y Cambeiro (2018). La rúbrica comprende cinco dimensiones, y para cada dimensión se establecen tres niveles de desempeño siendo el 1 el más bajo y el 3 el más alto. Cada dimensión queda definida por una serie de destrezas implicadas en la práctica de indagación. 
TABLA 3

Niveles de desempeño para la evaluación de destrezas de actividades de indagación (adaptado de Crujeiras y Cambeiro, 2018).

\begin{tabular}{|c|c|c|c|}
\hline Dimensión & Niveles de desempeño & & \\
\hline & & 2 & 1 \\
\hline $\begin{array}{l}\text { Planificación de } \\
\text { la investigación }\end{array}$ & $\begin{array}{l}\text { Diseña procedimientos y no } \\
\text { tiene dificultades } \\
\text { identificar variables }\end{array}$ & $\begin{array}{l}\text { Diseña procedimientos y tiene } \\
\text { algún problema para identificar } \\
\text { variables }\end{array}$ & No diseña procedimientos \\
\hline $\begin{array}{l}\text { Observación } \\
\text { toma de datos }\end{array}$ & $\begin{array}{l}\text { Analiza las propiedades y no } \\
\text { tiene dificultades para } \\
\text { relacionar causa-efecto de los } \\
\text { resultados obtenidos }\end{array}$ & $\begin{array}{l}\text { Analiza las propiedades y tiene } \\
\text { algún problema para relacionar } \\
\text { causa-efecto de los resultados } \\
\text { obtenidos }\end{array}$ & $\begin{array}{l}\text { No analiza propiedades, ni } \\
\text { establece relaciones con el } \\
\text { procedimiento seguido }\end{array}$ \\
\hline $\begin{array}{l}\text { Presentación } \\
\text { información }\end{array}$ & $\begin{array}{l}\text { Sabe explicar } \\
\text { procedimiento, entiende lo } \\
\text { que explica y lo justifica } \\
\text { científicamente }\end{array}$ & $\begin{array}{l}\text { Sabe explicar el procedimiento, } \\
\text { pero muestra dificultades en } \\
\text { entender lo que explica y en } \\
\text { justificarlo científicamente }\end{array}$ & $\begin{array}{l}\text { Muestra dificultades para } \\
\text { explicar el procedimiento y } \\
\text { no justifica los hechos } \\
\text { científicamente }\end{array}$ \\
\hline $\begin{array}{l}\text { Interpretación de } \\
\text { resultados }\end{array}$ & $\begin{array}{l}\text { Relaciona los resultados con } \\
\text { las variables de la reacción y } \\
\text { con el procedimiento seguido }\end{array}$ & $\begin{array}{l}\text { Tiene dificultades en relacionar } \\
\text { los resultados con las variables } \\
\text { de la reacción y con el } \\
\text { procedimiento seguido }\end{array}$ & $\begin{array}{l}\text { No relaciona los resultados } \\
\text { con las variables de la } \\
\text { reacción y con el } \\
\text { procedimiento seguido }\end{array}$ \\
\hline $\begin{array}{l}\text { Establecimiento } \\
\text { de conclusiones }\end{array}$ & $\begin{array}{l}\text { Es capaz de definir el } \\
\text { procedimiento óptimo* una } \\
\text { vez analizados los resultados }\end{array}$ & $\begin{array}{l}\text { Tiene dificultades en establecer } \\
\text { el procedimiento óptimo* }\end{array}$ & $\begin{array}{l}\text { No concluye en establecer el } \\
\text { procedimiento óptimo* }\end{array}$ \\
\hline
\end{tabular}

* óptimo en nuestro caso será aquel procedimiento que permite analizar la biodegradabilidad del plástico en las condiciones más sencillas posibles.

\section{Resultados}

\section{Fase 1:}

\section{Actividades Previas: TP polimerización de la caseina}

Con esta actividad práctica de laboratorio introducimos al alumnado en el trabajo científico, trabajando destrezas propias de los TP como son: dosificación, mezclado, filtrado, evaporación, cambio químico o secado y en reacciones de polimerización.

Durante el desarrollo del proceso para la obtención de un plástico a partir de la caseína de la leche, los alumnos observaron el procedimiento y sus variables, experimentaron y manipularon. Estas muestras, obtenidas por los diferentes grupos de trabajo, tenían aspectos distintos "vuestra muestra es más grande que la nuestra”. Les llamó mucho la atención la rotura de la miscela de la caseína al bajar el pH (al añadir el vinagre), y la formación del precipitado (“¿cómo podía estar este precipitado en la leche?”). También "observaron” a través de otros sentidos, “¿así huele el vinagre caliente?” y sobre todo les sorprendió el cambio químico al ver como se había trasformado el precipitado de la proteína de la caseína (inicialmente tenía un aspecto húmedo y grumoso, no estaba ligado), en una fina lámina no flexible, similar a una oblea.

Algunos comentarios o cuestiones que se fueron planteando a lo largo del proceso fueron: "¿Cuándo echamos el ácido acético?”, “¡hay que calentar más?”, “¡echamos más ácido?”, “¡ya se puede filtrar?”, “¿cómo separamos el residuo formado?”, “¿cómo quitamos la humedad residual del precipitado?”, “¿cómo extendemos el precipitado?", "ha quedado el residuo muy húmedo hay que volver a filtrar”.

En la Figura 2 se muestran imágenes del proceso desarrollado por los alumnos. 

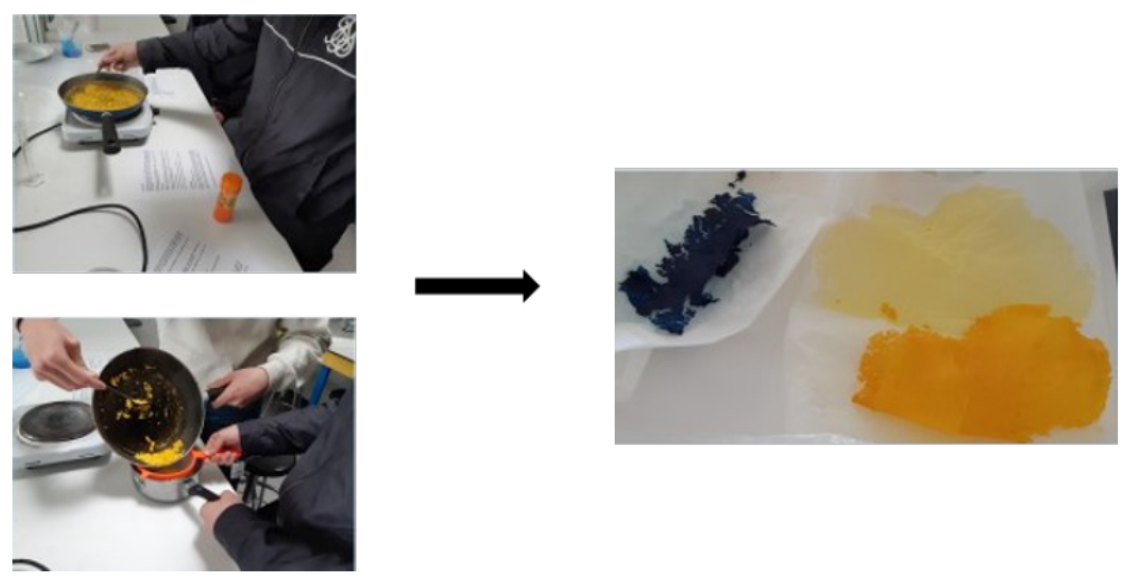

FIGURA 2

Actividad previa: TP polimerización de la caseína. Proceso y muestras obtenidas.

\section{Fase 2:}

\section{Actividad 1: Debate}

Los alumnos supieron responder a las preguntas que se les plantearon antes del inicio de la actividad. Definieron la problemática de los plásticos en la actualidad, valorando al mismo tiempo la necesidad de su uso. Expusieron las líneas de trabajo que se están desarrollando para amortiguar el problema medioambiental, presentando materiales alternativos con los que se está trabajando.

Los grupos en los que se dividió la clase para el desarrollo del debate llegaron a la conclusión de que el problema no está en los plásticos en sí, sino en el consumo excesivo y la gestión de los mismos. Los alumnos han construido argumentos fundamentados en fuentes científicas, que han expuesto a lo largo del desarrollo del debate. Por otro lado, se han hecho conscientes de lo que es un plástico y las variables que intervienen en su degradación. A continuación, se muestran frases transcritas de la grabación del debate.

"El plástico es un polímero derivado del petróleo. (...) Se está intentando hacer plásticos biodegradables para solucionar el problema de acumulación en la naturaleza. A los plásticos actuales solo les afectan los rayos UV por eso tarda tanto en desaparecer. A los nuevos plásticos que se están haciendo ya les afectan la temperatura o algunos microorganismos para que se descompongan más rápido”.

"El problema de los plásticos es la acumulación. Usamos plásticos que no se degradan fácilmente y se acumulan. En los próximos 50 años, va a haber más plásticos que peces. (...) Hay que hablar de reciclaje. La gente no reutiliza. El problema es el alto consumo. Hay que reducir el consumo. (...) Hay que tomar decisiones y gestionarlos mejor".

Y por último emitieron sus hipótesis: "El uso de plásticos es un perjuicio para el medio ambiente", "si usas plásticos, pero que sean biodegradables, desaparece el problema de la acumulación”, "la única forma de usar plásticos y no dañar al medio ambiente es reutilizar los que ya existen”.

\section{Actividad 2: TP: plastificación de almidón}

Una vez analizado el problema actual de los plásticos, los alumnos debían comprender qué es un bioplástico (químicamente hablando). A partir de ahí se les planteó el reto de desarrollar un procedimiento operativo para la fabricación de un biopolímero partiendo de almidón de maíz. Se proporcionó a los alumnos 
indicaciones para la producción de plástico a partir de almidón (Avellán, Díaz, Mendoza, 2020), y se les pidió que desarrollasen el procedimiento completo sin fijar algunas variables (como la temperatura a la que debían calentar, el tiempo de calentamiento o las cantidades exactas de ácido o plastificante a añadir), para que fueran conscientes de la importancia del método científico y lo que afecta el procedimiento en los productos de una reacción. El objetivo que se plantea es que los alumnos conozcan el proceso de obtención de un plástico, además de que identifiquen problemas o dificultades, diseñen estrategias de resolución de problemas, identifiquen las variables de la reacción, las relacionen con los productos obtenidos (causa-efecto), y que sean capaces de explicar y entender lo que ha sucedido. Trabajaron en parejas, formando tres grupos de trabajo.

En la figura siguiente se muestran imágenes de la secuencia de plastificación del almidón.

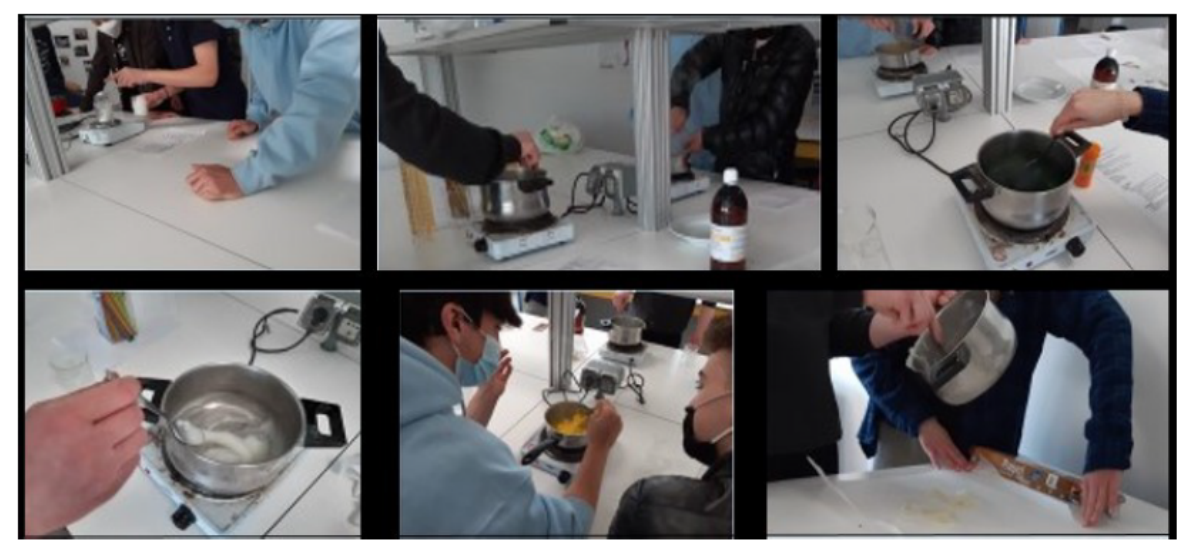

FIGURA 3

Secuencia del TP “plastificación almidón”.

Todos los grupos identificaron las variables de la reacción, pudieron ver el efecto de los cambios en los procedimientos llevados a cabo (por ejemplo, en la formación de grumos según se disolvía el almidón en agua caliente o agua fría), y pudieron caracterizar los films según su flexibilidad, transparencia, rigidez y aspecto. Los propios alumnos buscaron la justificación a la diferencia de flexibilidad y maleabilidad entre dos de los plásticos (a mayor \% de plastificante la muestra es más flexible, o a menor \% de ácido la muestra es más viscosa). Plantearon la hipótesis de que era debido al efecto plastificante de la glicerina, que incrementa el espacio intermolecular y permite la movilidad de las cadenas de enlaces. Decidieron realizar un experimento adicional para comprobarlo y para ello llevaron a cabo dos reacciones de polimerización entre las que la única variable diferente fue el \% de plastificante. Los resultados les permitieron aceptar su hipótesis de partida.

En cuanto al procedimiento experimental, se encontraron con el problema de la incorporación del agua en el almidón. Los gránulos de almidón son insolubles en agua. Con las distintas iteraciones realizadas, un grupo concluye que el mejor método para incorporarlo es mezclándolo previamente en frío antes de calentar. Uno de los grupos tuvo que filtrar la primera prueba y perdió mucho material en el proceso de filtración. Este ejercicio les condujo a concluir que la composición de la mezcla cambió, ya que se perdió almidón, y por tanto aumentó la proporción de plastificante, adquiriendo la muestra un aspecto gelatinoso. Uno de los grupos no se atrevió a filtrar porque tenía el producto muy viscoso y se puede observar en su film un aspecto granular (ver figura 4). 


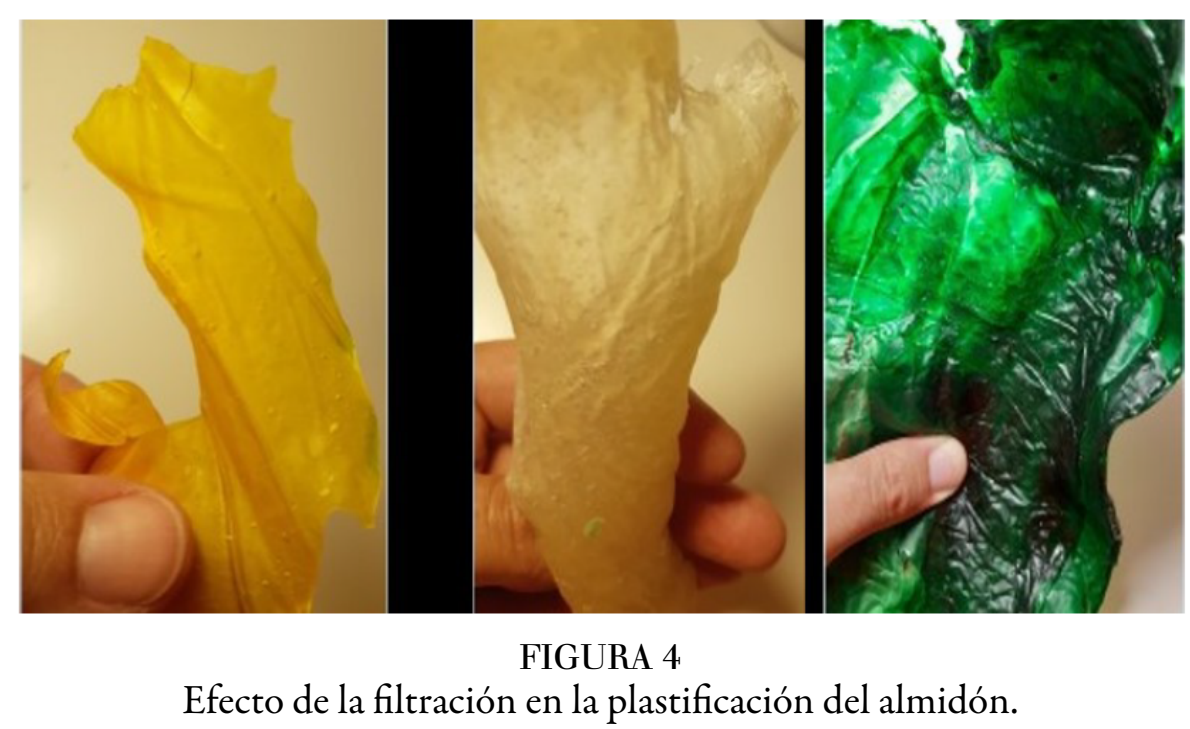

En dos de los grupos se pudo ver que el producto era una muestra muy pequeña. Concluyeron que habían tenido una pérdida de material. Los alumnos recurrieron a la ley de Lavoisier y la conservación de la materia, y concluyeron que se podría haber pesado la mezcla antes, la mezcla final y el residuo del filtro. Así se vería que también hay que considerar la pérdida de agua debida a la evaporación.

Sobre el cambio químico, todos los grupos pudieron observar efectos visuales del cambio químico identificando el momento exacto en que la mezcla empezaba a cambiar de aspecto aumentando su viscosidad. Pusieron nombre a ese momento como el de inicio del proceso de polimerización. Este momento venía precedido por un aumento en la evaporación y dedujimos entre todos que la reacción era de policondensación. Hubo un grupo que notó diferencia entre las dos pruebas. En una de ellas el cambio químico fue instantáneo, y explicaron que se debía a que antes de incorporar la glicerina la mezcla ya estaba caliente. La mezcla almidón-agua en ese caso se notaba menos fluida, tenía el aspecto de gel, y explicaba el proceso de gelatinización que sufre el almidón. Tal y como habíamos visto en las actividades previas de la Fase 1, se trataba del proceso de pérdida de cristalinidad del almidón y la solubilización de la amilosa.

Sobre el efecto del ácido en esta reacción, uno de los grupos empezó la reacción sin ácido acético (vinagre), pero observaron que la reacción se había iniciado porque vieron que había un cambio de viscosidad. Concluyeron que la teoría de que el ácido actúa de iniciador de reacción para abrir las cadenas parece que no se cumplió en esta reacción. La docente explicó que es posible que únicamente con la polaridad del agua sea suficiente para suplir esa función del ácido. Uno de los grupos comentó que en su primera reacción habían notado la formación de muchos grumos y un producto muy denso. Comentaron que habían dosificado menos proporción de ácido de lo que correspondía, y notaron que la mezcla había sido más espesa que la segunda que tenía la proporción de ácido correcta. La docente explicó que el ácido también hace el efecto de limitador de cadena y corta la reacción de polimerización, bajando la viscosidad del producto.

En esta actividad, el alumnado se ha formulado preguntas basadas en lo que iban observando a lo largo de la experimentación. Han sabido formular hipótesis que han comprobado realizando una nueva actividad experimental, han explorado con los reactivos y las variables de reacción y han sabido interpretar la información analizando las muestras obtenidas tras cada experimento.

\section{Actividad 3: Puesta en común de los resultados}

Para poder trabajar la competencia de la argumentación, en esta sesión los alumnos presentan los trabajos prácticos realizados con una explicación de los procedimientos seguidos, y las diferencias de los productos 
obtenidos. A partir de los resultados, el profesor introduce en esta sesión la explicación del proceso de cambio químico que ha experimentado el almidón basada en García (2015).

Una vez que los alumnos pudieron comparar los plásticos obtenidos entre ellos, concluyeron que, a pesar de que todos contaban de partida con los mismos materiales (almidón, glicerina, ácido y agua), se obtuvieron productos diferentes, y que el procedimiento de trabajo seguido en una reacción química influye en el resultado. En la figura 5 se muestran las muestras obtenidas por los distintos grupos de trabajo donde se observan algunas de las diferencias entre ellas.

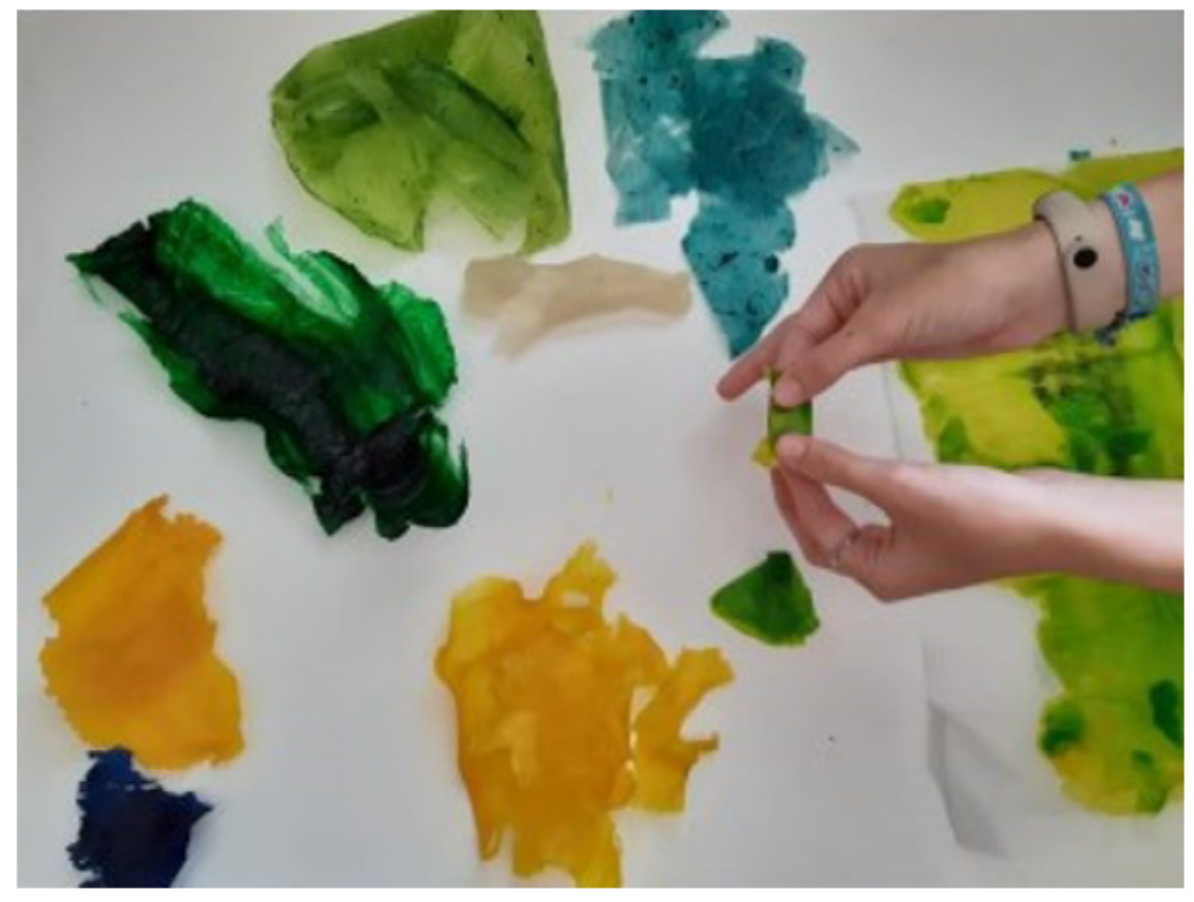

FIGURA 5

Muestras plásticas obtenidas.

En esta actividad de puesta en común los alumnos han comparado las muestras, buscado explicación a la diferencia en el aspecto (rugosidad, flexibilidad y tamaño) entre las muestras de cada equipo, buscando justificación en el desarrollo de cada proceso de obtención de la muestra, es decir, han identificado las variables del proceso que habían modificado en cada caso y han justificado así el cambio en el aspecto de la muestra obtenida. Con toda la información obtenida, han sacado conclusiones como: "según las cantidades que añadimos de los reactivos, el resultado cambia mucho", "te tienes que ir apuntando todo lo que añades, porque si lo quieres repetir y cambias algo, no obtienes lo mismo", "parecía imposible que fuéramos a obtener un plástico a partir de maíz".

\section{Actividad 4: Trabajo práctico "Modelizar test biodegradabilidad"}

Una vez que el alumnado conoce, de manera práctica, qué es un plástico y en qué consiste el proceso de plastificación, para poder tomar decisiones sobre el uso de los plásticos, debe tener conocimientos sobre su gestión. Uno de los argumentos del debate fue que los plásticos se acumulan debido a que tardan mucho en descomponerse. En el proyecto introducimos la degradabilidad de los plásticos como una vía para mejorar la gestión de los mismos.

En esta actividad, la docente les pidió a los alumnos que, a través de la lectura de artículos científicos (Castillo et al., 2015; Avellán, Díaz y Mendoza, 2020), intentaran diseñar un test de biodegradabilidad de 
plásticos que permitiera responder a las siguientes preguntas: ¿cuál de los plásticos que tenemos sobre la mesa es más biodegradable? ¿cómo podemos comprobarlo? Para ello dispusieron de bolsas de plástico comerciales que ellos mismos utilizan en el día a día.

Para empezar con esta actividad el alumnado inicialmente tuvo que reconocer los factores que afectan a la reacción de degradación de los materiales plásticos mediante un enfoque metodológico de indagación, que favorece la motivación y, en último término el aprendizaje de los estudiantes (Mazas, Cascarosa y Mateo, 2021). Trabajar a través del planteamiento de preguntas y buscando soluciones a las cuestiones que ellos mismos van encontrando, hace que los alumnos se muestren más involucrados y son más responsables durante el procedimiento (López y Franco, 2021). Tras la lectura de los artículos proporcionados por la docente, se concluye que para degradar un plástico es necesario romper el enlace carbono-carbono. Contextualizando el test de biodegradabilidad en el caso de la problemática medioambiental, en la que los plásticos se degradan según las condiciones ambientales, los alumnos concluyen que los factores a tener en cuenta son, entre otros, los rayos UV, la humedad y microorganismos. Una vez que se conocen los factores que afectan a la reacción de degradación de los plásticos, el concepto de biodegradación y los estándares que definen la degradación de un plástico (Avellán, Díaz y Mendoza, 2020), los alumnos están en disposición de iniciar el proceso de modelización de un test de biodegradabilidad. Los alumnos se dividen en dos grupos de trabajo y elaboran sus propuestas.

El primer grupo presenta el test de biodegradabilidad 1 que consiste en simular un posible contexto real, enterrando en tierra compost (con un 20\% de fiemo y humedad) un total de 6 muestras de bolsas de plástico que ellos mismos aportan. Las muestras tienen un tamaño de $4 \mathrm{x} 4 \mathrm{~cm}$ (figura 6). Mantienen este test durante 95 días y realizan un seguimiento semanal de las muestras. Para ello desentierran las muestras, las lavan, las secan y las pesan para comprobar el \% de pérdida en peso. El objetivo es comprobar si los plásticos testeados cumplen el estándar europeo EN 13432 en degradación física. Según esta norma, los plásticos biodegradables deben descomponerte un $90 \%$ en 180 días $\left(\mathrm{a} 58^{\circ} \mathrm{C}\right.$ ), o bien en condiciones normales deben tener esa pérdida en 95 días, mientras que los plásticos de origen fósil como el polietileno tardan en descomponerse en su totalidad entre 100-300 años (Chacón, Pacheco y Cendejas, 2016).

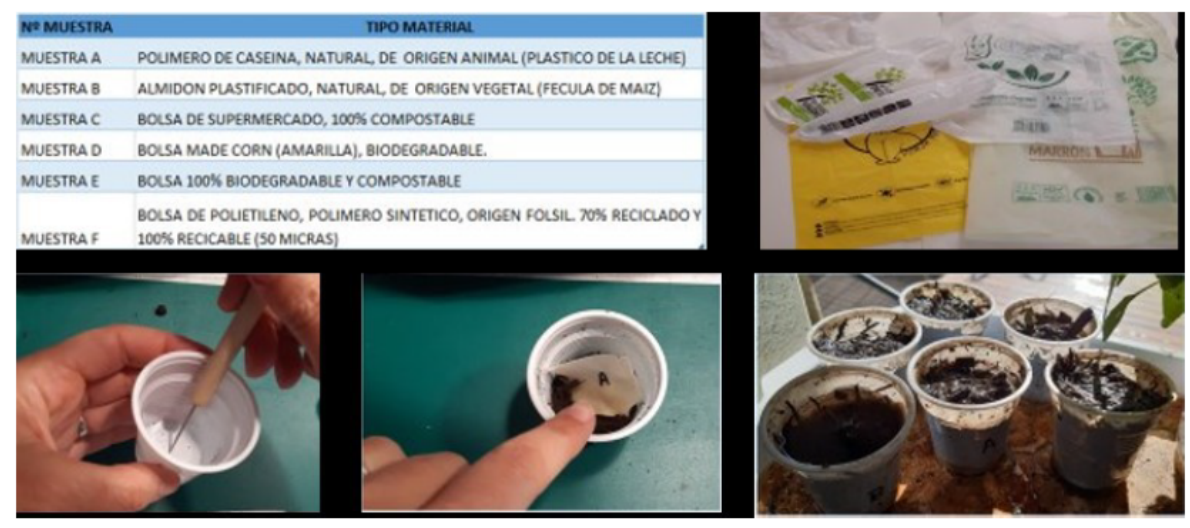

FIGURA 6

Detalle realización test biodegradabilidad 1.

A su vez, el segundo grupo presenta el test de biodegradabilidad 2 que consiste en testear 4 bolsas ( 2 bolsas comerciales marcadas como biodegradables, un bolsa de fécula de patata y otra bolsa shopper del Mercadona), todas ellas marcadas como $100 \%$ compostables, y comprobar los efectos en tierra con microorganismos, en concreto con presencia de lombriz roja rallada (Eisenia Foetida), y así comprobar si los plásticos testeados cumplen el estándar europeo EN 13432 y el estándar australiano AS 4736 que es la más exigente al incluir la prueba de lombriz, en la que se usa un compost con presencia de lombrices y éstas deben sobrevivir a lo largo de la prueba. 
Pasados los 95 días, los alumnos del primer grupo son capaces de concluir que los polímeros naturales como la caseína y el almidón plastificado (muestras A y B) se descomponen al 100\% entre 15 y 40 días, dando así cumplimiento al estándar europeo EN 13432, mientras que los polímeros marcados como biodegradables de las bolsas comerciales alcanzan una pérdida en peso entre el 20 y $26 \%$ con el test propuesto. Sin embargo, los polímeros sintéticos como el polietileno tan apenas presentan una pérdida en peso del 5,6\%, confirmando su baja velocidad de degradación.

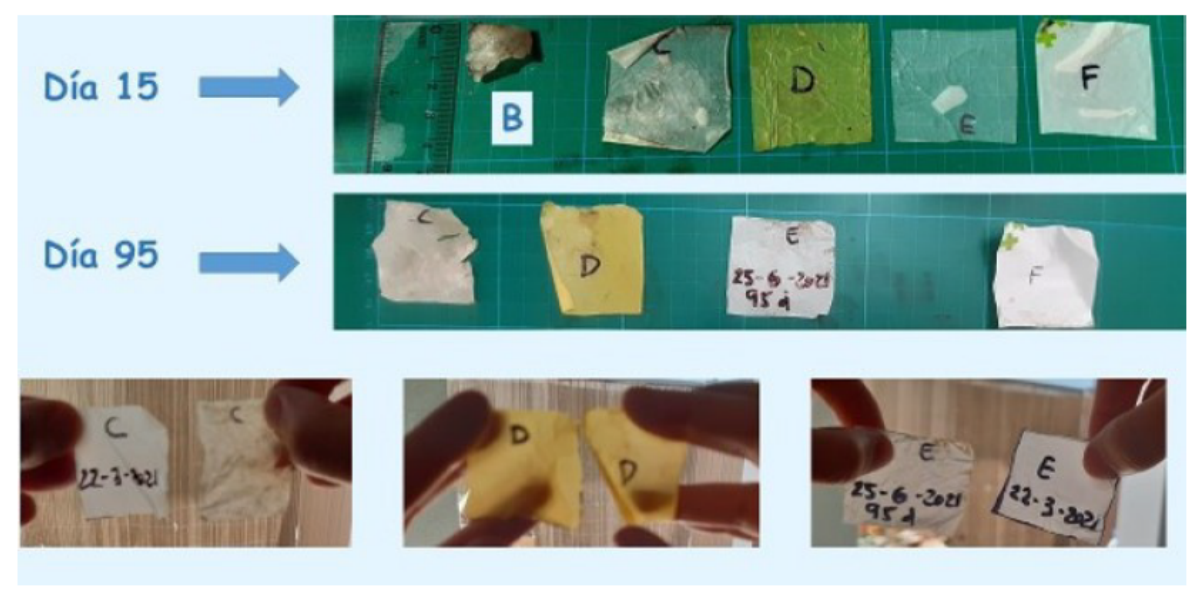

FIGURA 7

Resultados test biodegradabilidad 1.

Pasados los 54 días, los alumnos del segundo grupo son capaces de concluir que los cuatro plásticos testeados cumplen dentro de la prueba de ecotoxicidad (efecto en las plantas) la norma australiana (AS 4736), ya que las lombrices han sobrevivido a lo largo de la prueba. A los alumnos les ha sorprendido la alta biodegradabilidad que presentan las bolsas de almidón de patata y la bolsa shopper, con un 46\% y $43 \%$ de perdida en peso respectivamente, mientras que las otras dos bolsas comerciales solo presentan el 21 y el 13\% de perdida en peso.
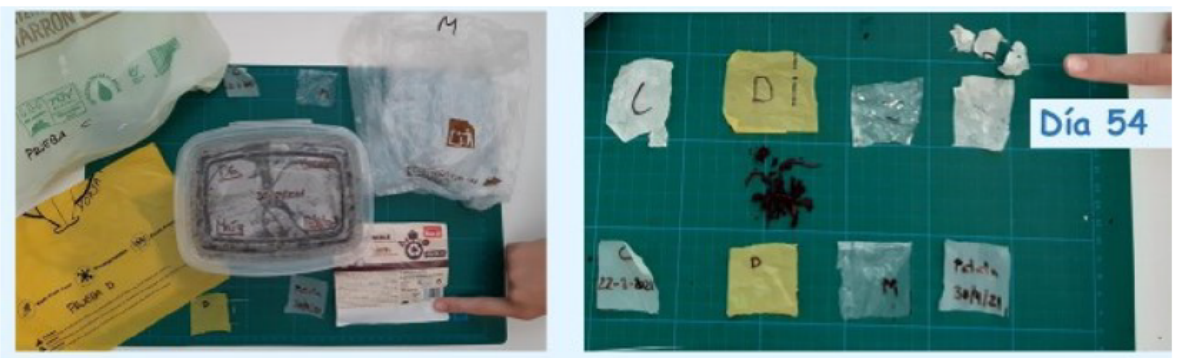

FIGURA 8

Resultados test biodegradabilidad 2.

Finalmente, los alumnos unifican en una tabla todos los datos obtenidos con los dos test modelizados para poder comparar ambos test y extraer conclusiones que conduzcan a modelizar un único test (ver Anexo I).

El alumnado analizó los datos recogidos en todos los casos y llegaron a las siguientes conclusiones:

- La bolsa de almidón de patata es la más biodegradable de todas, con una pérdida de peso del $46 \%$, mientras que la bolsa de polietileno (polímero sintético) es la menos biodegradable de todas, con una pérdida en peso del $5 \%$. Se preguntan si es proporcional esta pérdida de peso y si pasados los 117 días la muestra P (de almidón de patata) se habrá degradado al 100\%, y si la bolsa de polietileno va a necesitar 1.900 días (más de 5 años), en desaparecer al $100 \%$. 
- Concluyen que la muestra M (bolsa shopper del Mercadona) también es muy biodegradable con un 43\% de pérdida en peso. En base a los resultados obtenidos, predicen que esta bolsa también está hecha con un bioplástico, aunque no está marcado el origen del mismo (almidón maíz, patata, ácidos polilácticos, poliésteres alifáticos, polisacáridos, ...).

- Expresan su sorpresa ante la diferencia de peso de los materiales, ya que la bolsa $\mathrm{M}$ a simple vista parece ser la más fina de todas y tiene un peso inicial de $0,044 \mathrm{~g}(4 \mathrm{x} 4 \mathrm{~cm})$ mientras que la muestra $\mathrm{D}$ es más ligera con $0,03 \mathrm{~g}(4 \mathrm{x} 4 \mathrm{~cm})$.

- Les sorprende, que a pesar de no notar cambios a simple en la muestra $\mathrm{D}$, al pesar los restos de los plásticos a los 95 días, esta muestra ha tenido más pérdida en peso (26\%) que las muestras C y E, 23 y $20 \%$ respectivamente, que a simple vista parecen más degradadas.

- Los alumnos encuentran dificultades para comparar los dos test de biodegradabilidad. Solo pueden comparar los resultados de las mismas muestras, en este caso las muestras $\mathrm{C}$ y $\mathrm{D}$ que se repiten con ambos test. Observan que, mientras la pérdida en peso de la muestra $C$ es similar en ambos test $(0,126$ y $0,13 \%)$, en el caso de la muestra $\mathrm{D}$, la pérdida en peso con el segundo test es el doble que con el primero $(0,185 \%$ frente a $0,084 \%)$. Hay que tener en cuenta que el primer test duró 95 días mientras que el segundo test tuvo una duración de 54 días, así que con estos resultados predicen que el segundo test presenta condiciones de biodegradabilidad más agresivas que el primero, y lo justifican porque, a pesar de que las condiciones de humedad y de sustrato son las mismas, en el segundo test se cuenta además con la lombriz rallada roja.

En esta última actividad los alumnos trabajan la indagación y también la modelización. Observan lo que ocurre con las muestras plásticas a lo largo del tiempo que dura el proceso de degradabilidad, se formulan preguntas (“¿será proporcional la degradación de la muestra en el tiempo si el test durara el doble de tiempo?”), emiten hipótesis (“si los test tuvieran la misma duración, el test 2 es más efectivo”), experimentan y manipulan, exploran, interpretan la información obtenida (los resultados en \% en pérdida de peso de las muestras), explicar lo que está ocurriendo y usan modelos establecidos previamente en publicaciones científicas.

A continuación, se presentan los resultados de la rúbrica diseñada para evaluar los desempeños. 
TABLA 4

Resultados de la rúbrica de evaluación de destreza en actividades de indagación.

\begin{tabular}{|c|c|c|c|c|c|c|c|c|c|c|}
\hline \multirow[t]{2}{*}{ Dimensión } & \multirow[t]{2}{*}{ Ítems propuestos } & \multicolumn{3}{|c|}{ Grupo 1} & \multicolumn{3}{|c|}{ Grupo 2} & \multicolumn{3}{|c|}{ Grupo 3} \\
\hline & & 3 & 2 & 1 & 3 & 2 & 1 & 3 & 2 & 1 \\
\hline \multirow[t]{3}{*}{$\begin{array}{l}\text { Planificación de } \\
\text { la investigación }\end{array}$} & $\begin{array}{l}\text { Diseña procedimientos que permitan responder a la cuestión } \\
\text { planteada }\end{array}$ & 3 & & & & 2 & & 3 & & \\
\hline & $\begin{array}{l}\text { Modifica el procedimiento para solucionar problemas } \\
\text { detectados }\end{array}$ & 3 & & & 3 & & & 3 & & \\
\hline & Identifica las variables de la reacción & 3 & & & & 2 & & 3 & & \\
\hline \multirow{2}{*}{$\begin{array}{l}\text { Observación y } \\
\text { toma de datos }\end{array}$} & Analiza las propiedades de los productos obtenidos & 3 & & & 3 & & & 3 & & \\
\hline & $\begin{array}{l}\text { Relaciona causa-efecto del procedimiento seguido en base a } \\
\text { pruebas }\end{array}$ & 3 & & & & 2 & & 3 & & \\
\hline \multirow[t]{2}{*}{$\begin{array}{l}\text { Presentación de } \\
\text { información }\end{array}$} & $\begin{array}{l}\text { Sabe explicar el procedimiento seguido en base a objetivos } \\
\text { marcados }\end{array}$ & 3 & & & 3 & & & 3 & & \\
\hline & Entiende lo que explica y lo justifica científicamente & 3 & & & & 2 & & 3 & & \\
\hline \multirow{3}{*}{$\begin{array}{l}\text { Interpretación } \\
\text { de resultados }\end{array}$} & Explica el fenómeno observado en base a la teoría & 3 & & & & 2 & & & 2 & \\
\hline & Relaciona los resultados con las variables de reacción & 3 & & & & 2 & & 3 & & \\
\hline & $\begin{array}{l}\text { Analiza los datos extraídos y los relaciona con el } \\
\text { procedimiento seguido }\end{array}$ & 3 & & & 3 & & & 3 & & \\
\hline \multirow{3}{*}{$\begin{array}{l}\text { Establecimiento } \\
\text { de conclusiones }\end{array}$} & Utiliza los datos obtenidos para establecer conclusiones & 3 & & & & 2 & & 3 & & \\
\hline & Identifica problemas y define el procedimiento óptimo & 3 & & & & 2 & & 3 & & \\
\hline & $\begin{array}{l}\text { Analiza el procedimientos seguido, el producto obtenido y } \\
\text { determina el procedimiento idónea }\end{array}$ & 3 & & & & 2 & & 3 & & \\
\hline
\end{tabular}

Los resultados muestran altos niveles de desempeño, especialmente en las dimensiones relativas a la planificación de la investigación y el diseño de pruebas, en la observación, en la búsqueda y presentación de la información y el establecimiento de conclusiones. Resulta llamativo que haya dos grupos (de los tres) con un desempeño tan alto en planificación de investigación y diseño de procedimientos científicos, y que, a pesar de no conocer la reacción de polimerización, hayan podido obtener buenos resultados en las muestras plásticas, salvando los problemas que se encontraban a lo largo de la práctica, como la presencia de grumos o la falta de evaporación en el producto final. Se observa que los resultados relativos a la interpretación de resultados en base a los conocimientos previos no están tan desarrollados en general, en parte debido a la complejidad de las reacciones trabajadas y a no estar familiarizados con este tipo de materiales.

\section{Actividad 5: Conclusiones "plásticos sí, plásticos no"}

Una vez llegados al final del proyecto, los alumnos retoman sus hipótesis de partida sobre el uso de los plásticos. Con la información recopilada a lo largo del desarrollo de las actividades, revisaron sus hipótesis y la gran mayoría expresa que siguen creyendo que el uso tan desmesurado de plásticos no beneficia al medioambiente y se podría intentar reducir. Comentan que si sustituimos el plástico por otro material que tampoco sea biodegradable nos pasará lo mismo. Por lo tanto, que además de reducir, la clave está en usar plásticos que se degraden naturalmente en poco tiempo: "ahora diría que sí al uso de plásticos siempre y cuando sean totalmente biodegradables”. Se observa que los argumentos del alumnado ya no son o sí o no, sino que argumentan razones a favor o en contra del uso de plásticos justificando sus respuestas en lo aprendido a 
lo largo del proyecto. Por ejemplo: "yo estoy ahora a favor del uso de plásticos siempre que sean totalmente biodegradables, porque veo que el problema no es usar plásticos, sino que los que usemos se puedan degradar y no dejen huella ambiental".

Aunque el planteamiento inicial fue trabajar principalmente una de las prácticas científicas en cada una de las actividades, la realidad es que en la mayoría de las actividades los alumnos ponen en juego diferentes operaciones. En la tabla siguiente se resumen las destrezas trabajadas en cada una de las actividades.

TABLA 5

Destrezas trabajadas en cada actividad.

\begin{tabular}{|c|c|c|c|}
\hline & Indagación & Argumentación & Modelización \\
\hline Actividad 0 & $\begin{array}{l}\text { Observan el procedimiento, } \\
\text { experimentan y manipulan. } \\
\text { Comparan resultados e } \\
\text { identifican variables } \\
\text { (interpretan información). }\end{array}$ & & \\
\hline Actividad 1 & $\begin{array}{l}\text { Se formularon preguntas que } \\
\text { concluyeron en hipótesis } \\
\text { (que comprobaron en las } \\
\text { siguientes actividades). }\end{array}$ & $\begin{array}{l}\text { Identificaron pruebas (en } \\
\text { artículos científicos) para } \\
\text { justificar sus argumentos. } \\
\text { Extraen conclusiones como } \\
\text { que el problema no es el } \\
\text { plástico en sí mismo sino su } \\
\text { mala gestión. }\end{array}$ & \\
\hline Actividad 2 & $\begin{array}{l}\text { Experimentan y manipulan, } \\
\text { observan el producto, } \\
\text { comparan entre los } \\
\text { obtenidos, plantean hipótesis } \\
\text { en relación a las diferencias } \\
\text { encontradas en los plásticos } \\
\text { producidos, plantean } \\
\text { experimento para corroborar } \\
\text { la hipótesis, interpretan los } \\
\text { resultados. }\end{array}$ & & $\begin{array}{l}\text { Explican el proceso de } \\
\text { plastificación y diseñan el } \\
\text { procedimiento óptimo. }\end{array}$ \\
\hline Actividad 3 & & $\begin{array}{l}\text { Comparan productos, } \\
\text { identifican variables, } \\
\text { encuentran pruebas y extraen } \\
\text { conclusiones (p.ej. la } \\
\text { temperatura a la que está la } \\
\text { mezcla al añadir la glicerina } \\
\text { afecta a la flexibilidad del } \\
\text { plástico obtenido). }\end{array}$ & \\
\hline Actividad 4 & $\begin{array}{l}\text { Observan la degradación de } \\
\text { las muestras, se formulan } \\
\text { preguntas, emiten hipótesis, } \\
\text { experimentan y manipulan, } \\
\text { exploran, interpretan los } \\
\text { datos obtenidos y sacan } \\
\text { conclusiones. }\end{array}$ & & $\begin{array}{l}\text { Reconoce los factores para } \\
\text { comprender el proceso de } \\
\text { degradación de un plástico (UV, } \\
\text { humedad y microorganismos). } \\
\text { Diseñan procedimiento de } \\
\text { análisis de biodegradabilidad y } \\
\text { utilizan modelos previos. }\end{array}$ \\
\hline Actividad 5 & & $\begin{array}{l}\text { Utilizan las pruebas obtenidas } \\
\text { a lo largo de la secuencia para } \\
\text { para construir su argumento } \\
\text { final. }\end{array}$ & \\
\hline
\end{tabular}




\section{Discusión y ConcLusiones}

En la presente intervención se describe una experiencia de indagación dirigida a través de preguntas, en la que el objetivo principal fue que los alumnos aprendieran ciencia a través del desarrollo de las prácticas científicas de indagación, argumentación y modelización.

El proyecto, nacido de la colaboración de la docente del centro y de los docentes de la Universidad, ha permitido trabajar con los alumnos la competencia científica en relación a un tema de actualidad que despierta en ellos un interés que se ha mantenido a lo largo del proyecto, ampliando así las pruebas sobre los beneficios de trabajar las prácticas científicas en el aula (Romero-Ariza, 2017). Partir de este tipo de actividades aseguran la participación activa del alumnado y por ende facilitan su aprendizaje (Cascarosa, Mazas, Martínez-Peña y Gil-Quílez, 2019).

Los resultados muestran que el diseño de actividades del proyecto ha servido para trabajar las prácticas científicas con los alumnos de $1^{\circ}$ de bachillerato, a pesar de que a priori, los cursos de bachillerato se consideran complejos para el desempeño de nuevos proyectos. Se puede concluir que los estudiantes han sabido observar lo que ocurre en detalle, emitir hipótesis, formularse preguntas, recoger pruebas y establecer conclusiones en base a esas pruebas, es decir, desarrollar gran parte de las prácticas científicas establecidas por algunos autores (Erduran y Jiménez-Aleixandre, 2007; Gilbert y Justi, 2016; Mosquera Bargiela, Puig y Blanco, 2018). Sin duda, los alumnos han llegado a conclusiones y han trabajado destrezas que sin este tipo de actividades no se habrían podido trabajar en una sesión convencional.

Con esta intervención se buscaba también que el alumno aplicara conocimientos frente a la memorización de contenidos (Crujeiras y Jiménez-Aleixandre, 2015), que "hablara ciencia", "practicara ciencia", participara de la cultura científica, de la producción y difusión de conocimiento, para ello es necesario el desarrollo de la capacidad de razonar o argumentar, en otras palabras, no solo aprender significativamente los conceptos implicados, o la mecánica de resolución de los problemas, sino también aprender el "qué" de las ciencias, participar en su forma de trabajar, en sus métodos, en su forma de enfrentarse a problemas auténticos. Para conseguirlo, las prácticas basadas en métodos de indagación han permitido, a través de oportunidades para investigar y comunicar los resultados de la experimentación, motivar a los estudiantes hacia la ciencia (González y Crujeiras, 2016). Es por eso que debemos seguir fomentando oportunidades y creando ambientes de aprendizaje en los que se demande al alumnado que resuelva problemas, que compare las soluciones dadas por distintos equipos y que argumente sus respuestas justificadas mediante una base científica.

Por último, valoramos muy positivamente la colaboración de los docentes de centros escolares y los docentes universitarios porque este tipo de colaboración nos permite a todos conocer la realidad de las aulas y diseñar en detalle proyectos personalizados para el grupo clase que favorecen el aprendizaje de los alumnos y la posibilidad de difundir datos de investigación educativa reales recogidos en el aula.

\section{Materiales SUPlementarios}

Anexo I (pdf)

\section{Agradecimientos}

Los autores agracen al alumnado y los docentes del Colegio Internacional Ánfora por su colaboración en esta investigación. El grupo BEAGLE de investigación apoya este trabajo, así como el Instituto IUCA, ambos de la Universidad de Zaragoza. 


\section{ReFERENCIAS}

Avellán A., Díaz D., Mendoza A. (2020) Obtención de bioplástico a partir de almidón de maíz. Revista Colón Ciencias, Tecnología y Negocios, 7(1).

Ariza M. R., Aguirre D., Quesada A., Abril A. M., García F. J. (2016) ¿Lana o metal? Una propuesta de aprendizaje por indagación para el estudio de las propiedades térmicas de materiales comunes. Revista Electrónica de Enseñanza de las Ciencias, 15(2), 297-311.

Bevins S., Price G. (2016) Reconceptualising inquiry in science education. International Journal of Science Education, 38(1), 17-29. https://doi.org/10.1080/09500693.2015.1124300

Caamaño A. (2018) Enseñar química en contexto. Un recorrido por los proyectos de química en contexto desde la década de los 80 hasta la actualidad. Educación química, 29(1), 21-54. https://doi.org/10.22201/fq.18708404 e.2018.1.63686

Cascarosa E., Mazas B., Martínez-Peña B., Gil-Quílez M. J. (2019) What do students think they should know about vertebrate fish? Journal of Biological Education. https://doi.org/10.1080/00219266.2019.1620313

Castillo R., Escobar E., Fernández D., Gutiérrez R., Morcillo J., Núñez N., Peñaloza S. (2015) Bioplásticos a base de la cáscara de plátano. Revista de Iniciación Cientifica, 41, 34-37.

Chacón M., Pacheco A., Cendejas M., Ortega F. (2016) Tendencia del crecimiento en la cultura del reciclaje. Revista de Ciencias Ambientales y Recursos Naturales 2(5), 63-72.

Couso, D. (2014) De la moda <<aprender indagando>> a la indagación para modelizar: una reflexión crítica. XXVI Encuentro de Didáctica de las Ciencias Experimentales. Huelva: Servicio de Publicaciones de la Universidad de Huelva.

Crawford B. A. (2007) Learning to teach science as inquiry in the rough and tumble of practise. Jorunal of research in science teaching, 44(4), 613-642

Crujeiras-Pérez, B., Brocos, P. (2021). Pre-service teachers' use of epistemic criteria in the assessment of scientific procedures for identifying microplastics in beach sand. Chemistry Education Research and Practice, 22(2), 237-246. http://dx.doi.org/10.1039/DORP00176G

Crujeiras B., Jiménez-Aleixandre M. P. (2015) Desafíos planteados por las actividades abiertas de indagación en el laboratorio: articulación de conocimientos teóricos y prácticos en las prácticas científicas. Enseñanza de las Ciencias, 33(1), 63-84. http://dx.doi.org/10.5565/rev/ensciencias.1469

Crujeiras B., Cambeiro F. (2018) Una experiencia de indagación cooperativa para aprender ciencias en educación secundaria participando en las prácticas científicas. Revista Eureka sobre Enseñanza y Divulgación de las Ciencias, 15(1), 1201.https://doi.org/ 10.25267/Rev_Eureka_ensen_divulg_cienc.2018.v15.11.1201

Díaz N., Jiménez-Liso M. R. (2012) Las controversias sociocientíficas: Temáticas e importancia para la educación científica. Revista Eureka sobre Enseñanza y Divulgación de las Ciencias, 9(1), 54-70

Erduran S., Jiménez-Aleixandre M. P. (2007) Argumentation in Science Education. Perspectives from classroom-based Research. Berlín: Springer.

García-Carmona A. (2012) <<¿Qué he comprendido? ¿qué sigo sin entender?>>: promoviendo la autorreflexión en clase de ciencias. Revista Eureka sobre Enseñanza y Divulgación de las Ciencias, 9(2), 231-240.

García A. (2015) Obtención de un polímero biodegradable a partir de almidón de maiz. Santa Tecla: Enero.

Gilbert J., Justi R. (2016) Modelling-based Teaching in Science Education. Switzerland: Springer. https://doi.org/10. 1007/978-3-319-29039-3

González Rodríguez L., Crujeiras Pérez B. (2016) Aprendizaje de las reacciones químicas a través de actividades de indagación en el laboratorio sobre cuestiones de la vida cotidiana. Enseñanza de las Ciencias, 34(3),143-160. h ttp://dx.doi.org/10.5565/rev/ensciencias.2018

Hinojosa J., Snamartí N. (2015) La autorregulación metacognitiva como medio para facilitar la transferencia en mecánica. Revista Eureka sobre Enseñanza y divulgación de las Ciencias, 12(2), 249-263. https://doi.org/10.252 67/rev_eureka_ensen_divulg_cienc.2015.v12.i2.02 
Hodson D. (1994) Hacia un enfoque más crítico del trabajo de laboratorio. Enseñanza de las Ciencias, 12(3), 299-313. Jiménez-Aleixandre M. P., Díaz-de Bustamente J. (2003) Discurso de aula y argumentación en clase de ciencias: cuestiones teóricas y metodológicas. Enseñanza de las Ciencias, 21(3), 359-370.

Jiménez-Aleixandre M. P., Crujeiras B. (2017) Epistemic Practices and Scientific Practices in Science Education. En Keith S. Taber y Ben Akpan (Eds.), Science Education (pp. 69-80). Países Bajos: Sense Publishers.

Martin-Hansen L. (2002) Defining inquiry. The science teacher, 69(2), 34.

Mazas B., Cascarosa E., Mateo E. (2021) ¿Qué suena dentro de tu cuerpo? Un proyecto sobre el corazón en Educación infantil. Enseñanza de las Ciencias, 39(2), 201-221. https://doi.org/10.5565/rev/ensciencias.3213

Mosquera Bargiela I., Puig B., Blanco Anaya P. (2018) Las prácticas científicas en infantil. Una aproximación al análisis del currículum y planes de formación del profesorado de Galicia. Enseñanza de las Ciencias, 36(1), 7-23. https: $/ /$ doi.org/10.5565/rev/ensciencias.2311

Müller R. (2020) ¡Cuánta riqueza detrás de la leche! Revista Enseñanza de Química, 3, 153-169.

López M. M., Franco A. (2021) Indagación sobre la degradación de plásticos con estudiantes de secundaria. Educación Quimica, 32(2). https://doi.org/10.22201/fq.18708404e.2021.2.76553

OCDE (2016) PISA 201. Asseessment and Analytical Framework: Science, Reading, Mathematic and Finalcial Literacy. OEDC Publisching

Romero-Ariza M. (2017) El aprendizaje por indagación: ¿existen suficientes evidencias sobres sus beneficios en la enseñanza de las ciencias? Revista Eureka sobre Enseñanza y Divulgación de las Ciencias, 14(2), 286-299. Recuperado de: http://hdl.handle.net/10498/19218

Sadler T. D., Zeidler D. L. (2005) Patterns of informal reasoning in the context of socioscientific decisión making. Journal of Research in Science Teaching 42, 112-128. https://doi.org/10.1002/tea.20042

Uskola A., Burgoa B., Maguregi G. (2021) Integración del conocimiento científico en la argumentación sobre temas científicos. Revista Eureka sobre Enseñanza de las Ciencias, 18(1). https://doi.org/10.25267/Rev_Eureka_ense n_divulg_cienc.2021.v18.i1.1101

\section{INFORMACIÓN ADICIONAL}

Para citar este artículo: Cascarosa, E., Pozuelo, J. y Calvo, M.E. (2022) ¿Plásticos sí o plásticos no? Trabajando prácticas científicas con estudiantes de bachillerato. Revista Eureka sobre Enseñanza y Divulgación de las Ciencias 19(1), 1502.doi: 10.25267/Rev_Eureka_ensen_divulg_cienc.2022.v19.i1.1502 